\title{
Economic Modeling for the Renewable Energy Support
}

\author{
Sara Nada1, M. Hamed ${ }^{*}$ \\ ${ }^{1}$ Università degli Studi di Roma "Tor Vergata", Rome, Italy \\ ${ }^{2}$ Department of Electrical Engineering, Faculty of Engineering, Port Said University, Port Said, Egypt \\ Email: Sara nada14@hotmail.com, ${ }^{*}$ hamed639@hotmail.com
}

Received 28 March 2015; accepted 12 April 2015; published 17 April 2015

Copyright $@ 2015$ by authors and OALib.

This work is licensed under the Creative Commons Attribution International License (CC BY).

http://creativecommons.org/licenses/by/4.0/

(c) ()

\section{Abstract}

This paper presents a general economic modification for the present energy strategy. This modification is unidirectional economic concept depending on three principles. The paper explains shortly the basics of engineering connections between renewable energy stations and the traditional electric power networks, illustrating the technical rules while the economical base has been accounted with time consideration. Converting stations and rectification principles are priced, simply. Also, the cost comparison may be noted in order to find the best quick way for development. The proposed support depends on three axes as the technical (direct current distribution systems), financial banking, and industrial activity. This leads to a concentration in the manufactured equipments and devices to be capable for encourage the application of direct current operation. The tools and devices in the electric systems of cars may be the first key for the technical implementation as a stable actual market in the world so that the industrial axis would lead to the commercial use with a reduced price for each component due to the high growth in mass production. It is concluded that, the proposed philosophy can be introduced on the basis of government support through electric and industrial companies besides governmental banks. Also, encourage policy for private investment sectors in marketing and financial authorities may be needed where a simple economic model is illustrated. This is an economic differential solution since it accounts the price ratio for the aimed target.

\section{Keywords}

Economic, Banking, Marketing, Industrial Investment, Cost, Electric Station, Renewable Energy

Subject Areas: Electric Engineering

\section{Introduction}

The utilization of renewable energy (RE) to get clean energy is facing a difficulty from the economic point of "Corresponding author. 
view so that many researches aimed to treat the item. Feng et al., 2011 [1] tried to improve the gasification performance of biomass to produce a rich temperature gas and Zaki et al., 2011 [2] proposed an efficient method for energy analysis of gas turbine plants on the way to improve the energy generation depending on the natural air cooling. RE primarily consists of different projects as biomass-based power, co-generation power plants. Fernald et al. (2013) [3] have studied the experience and technical expertise in RE providing a platform to take advantage of the growing demand (population growth) for alternative power and fuel sources where they proposed the limits for biotechnologies in general. Gao and Razak, 2013 [4] have presented the influenced factors related to the urban area. The applied fields are changing in a wide range of activities although many sectors of $\mathbf{R E}$ depend on the information of technologies, publications, and marketing, including summaries of successful projects. A comprehensive source of information for a country, local, utility, and selected suitable RE would be a major study for future of humans on the universe (Tang, 2011) [5] while energy efficiency, energy security and climate change are vital issues (Phat, 2012) [6]. The quest for sustainable energy solutions is intense and companies, researchers and innovators are tackling the problem with a wide variety of approaches. The subject was important even for the economic level where Arslan and Ozturan (2011) [7] tried to shed light upon the strategic value of information technology (IT) investments. Previous literature suggests that IT investments per se are not sufficient for improving firm performance. Drawing from the resource-based view, it is hypothesized that IT investments can deliver higher firm performance if they are: 1) combined with complementary assets; 2) leveraged to build capabilities; and 3) used to support organizational core competencies. Also, Wan and Liang have presented risk management item in large services although $\mathbf{R E}$ is not similar to this type.

If the building energy storage is properly dimensioned (summer/winter), no other energy source is needed with powerful economic advantages (Khan and Islam, 2011 [8]). A thermal principle for energy storage is to achieve energy balance in stock where it's monitoring and control interacts with heat pumps and others. Consequentially, control systems are based on open technology over the Internet. Bio-energy (biodiversity, biomass basics, and biomass resources) represents a wealth of biomass feedstock information resources from laboratories and other research organizations (Derouiche et al., 2011 [9], and Mandal \& Chakraborty, 2011 [10]). So, development is partly based on original and industrial archival research as well as the untapped mass media record. Technical policy goes to the supporting style of solar and wind energies.

\section{Solar Energy}

As sunlight passes through the atmosphere, some of it is absorbed, scattered, and reflected according to many factors as: (air molecules, water vapor, clouds, dust, pollutants and natural disasters, and volcanoes). Atmospheric conditions reduce direct radiation by $10 \%-100 \%$ (clear dry-thick cloudy) days. USA solar resource is a good example for Photovoltaic (PV) systems due to the utilization of both direct and scattered sunlight. Concentrating solar power by concentrators needs a control system (Khan and Islam, 2011 [8]). Nowadays, residential and commercial solar energy grids, hybrid, and backup systems can be installed; where an inverter is required to convert power for consumers. Inverters pecification depends on maximum demand power for standard battery bank (12, 24 or $48 \mathrm{~V})$. It may be used for a grid-tie, grid-tie with battery backup or off-grid system since solar systems are healthy and efficient. Reliable solar inverter is needed in grid-connected $\mathbf{P V}$ and charge controller systems.

Khan and Islam (2011) [8] tried for the advancement of solar water heaters while solar grid lights in different variations were developed for office applications. Solar street lights are adaptable to the fast-paced evolution of technology and marketing which requires product enhancements, new designs, and quick turn-times. Usually, solar outdoor street lighting systems are designed for non-electrified rural areas because of reduced cost and low maintenance. The combination of excellent grants, incentives, and relative low cost of raw material makes this an excellent time to consider $\mathbf{R E}$ solutions today. The daily shortest sunny hours per a year (winters) is accounted for safe where the required generation at daylight can be estimated. It helps to get the cost of solar panels for actual energy consumption but their cost is high relative to the traditional. Initial solar panel cost (capital cost) is the biggest drawback although tax breaks can help a lot (encourage policy) with credits, rebates and incentives. Long-term systems are designed with reliable performance at low maintenance where they are a wide range of physical and operating environments. They are perfect for rural, suburban and metropolitan areas while new financing options are available to non-residential customers which significantly lower the financial barrier of entry into RE projects (Seacord et al., 2011) [11]. Wind power isn't convenient for residential areas as the wind flow is disrupted by buildings. 
The cost varies according some factors depending on the house hold size, the energy amount needed, the particular selected solar energy system, received sunshine in the area and available government funding policy. Concentrating solar power CSP technologies use mirrors to concentrate sunlight onto receivers to collect and convert it to heat so that this thermal energy can then be implemented for electric generation. PV materials and devices convert sunlight into electric energy where PV effect caused certain materials to convert light energy into electric at the atomic level. In many cases, PV power is the least expensive form of electricity for these tasks because there is no need for long wires (expensive part). Thus, solar power can help alleviate capacity problems on local grids and can reduce gas emissions by electricity decreasing from plants (Dwivedi et al., 2011) [12].

\section{Wind Energy}

Wind energy (WE) technologies use the energy in natural wind for practical purposes such as generating electricity, charging batteries, pumping water, and grinding grain. Most wind energy technologies can be implemented as stand-alone applications, connected to a utility power grid, or even combined with a PV system. For WE utility-scale sources, a large number of turbines are usually built close together to form a wind farm (WF) that provides grid power. Several electricity providers use WF to supply power to their customers. Stand-alone turbines are typically applied for water pumping or communications however, homeowners and farmers in windy areas can consider small wind systems for electric generation. It should be remarked that, a power plant would be fueled using virgin wood residues which, apart from the electricity production, are expected to produce emissions such as sulfur dioxide, nitrogen oxides and carbon monoxide. These emissions should be released at a size less than 10 microns in diameter. The Windy Point/Windy Flats wind will provide a maximum capacity while the overall development is partially completed with the Windy Point of WF consideration. Such WF should be constructed as big heavy projects since it can be divided into stages. The wind speed is a major factor before any others (Gomes and Cardoso, 2011) [13] as seen in Figure 1. A multi objective optimization is necessary to allocate PV and WF power into a network has been proposed (Ramirez, 2011) [14]. Clients can avail installation services of wind solar hybrid systems. Services of such systems are acknowledged for reliability and effectiveness since they are rendered with advanced technology and innovative ideas.

\section{Coupling with Electric Networks}

The major point in the united networks appears to be the coupling between different generating stations and all consumers so that this coupling must be done according to a technical rule. This leads to the synchronizing rule for the alternating Current (AC) generators in three items as: [same voltage value $\mathbf{V}$, same phase system sequence ABC, same speed (frequency $f$ )]. These three rules are given for the connection of a generator in three cases as: (to another generator, to a network, or the connection of a network part to another network section).

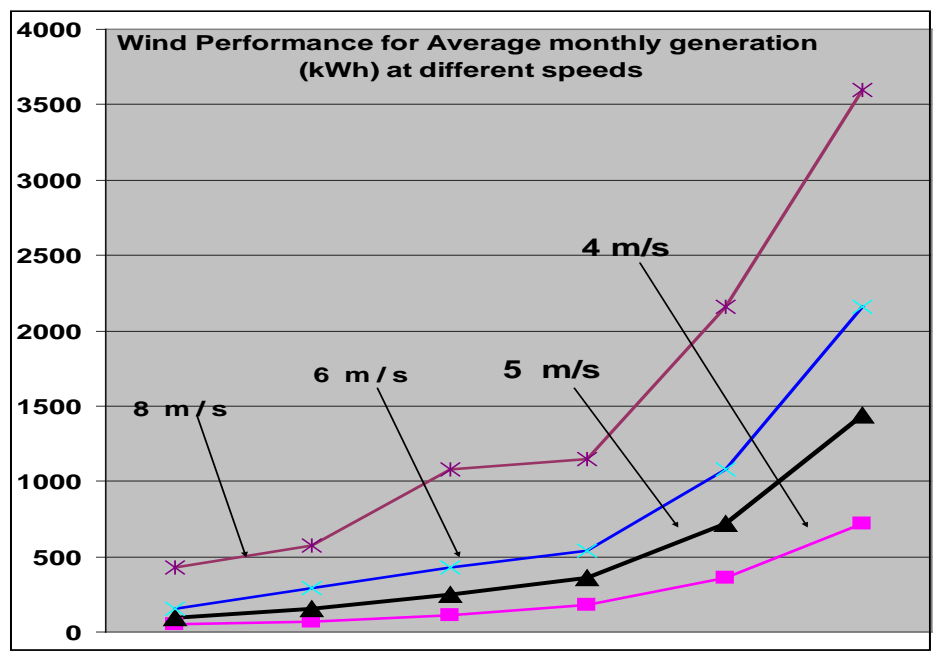

Figure 1. The electric generation performance with the wind speed. 
Since the generation of $\mathbf{R E}$ is always done on direct current (DC), the rules will be reduced to only the voltage value and polarity. Now, the connection between different sections and components of a network can be classified in the form:

1) Connection of AC side to another AC side is controlled by the basic three synchronizing rules above.

2) The connection between DC side and another DC section has only value and polarity rules. This case is defined as $\boldsymbol{D C}$ /DC Converter where power is taken from a voltage source, delivered to a load. Usually the Conversion is a voltage to a voltage, but sometimes it can be a voltage to a current (a $12 \mathrm{~V}$ battery varies between 9.6 and $14.4 \mathrm{~V}$, may be converted to $24 \mathrm{~V}$ that does not vary at all). There are two types of converters as step down and step up converters. In step down case, power is taken from a voltage source, delivered to a load, and the output voltage is always less than the input voltage.

3) The connection between a DC section and another AC side will have three different cases for operation according to the direction of power flow. In first case (AC/DC), the AC network will add a power to the renewable power at the site (renewable power $<$ the needed) so that $\boldsymbol{a}$ rectifier station will be required. In second case (DC/AC), the generated $\mathbf{R E}$ is always $>$ the needed so that the power excess may be transmitted through the united network. Thus, an inverter station could be necessary. Finally, in the general case (AC/DC or DC/AC), the inter-variation in the direction of power flow would be possible. So, DC power goes to the AC network in a certain time while this flow can be reversed in another. Thus, an inverter station must be installed. It should be mentioned that, the technical view for this connection between networks and RE installation (as given below) is the entry way for the economic evaluation in order to present the suitable proposal.

\subsection{Rectifiers}

Rectifier (diode) is a device which permits the current flow in only one direction. This means that the positive current passes through diodes while the negative currents will not pass at all. The diode performance differs from the resistance but it may be a nonlinear resistance (zero for a specified direction of current and infinity for the opposite). If the current has two parts positive and negative; diode passes only the positive part. Consequentially, there must be two terminals \{Anode (positive pole) and Cathode (negative pole)\}. It should be noted that, a current wave form is major to work with rectifiers as it may have different shapes (sinusoidal, rectangular, teeth, etc). It is usually utilized to transform the AC current into a DC current so that a lot of positive parts will be needed. There are many connections for the diodes in a circuit to gain a DC wave form. The Single Rectifier (unpractical) is a half wave rectification. Since the loss in the wave is a half of the wave form per a cycle, a new idea for modification may be introduced, leading to raise the waveform efficiency. The double connection for rectifiers is needed in a circuit (or a network) to increase the current (or voltage) value, raising the average current. This means that this connection is better and more efficient for the transformation from AC circuits into DC circuits because the waveform gives a higher average. It should be mentioned that the rules of rectification are improved. Multi rectifier connection can cover the required nominal load in the DC circuit. For single phase AC circuits, a high effective method for the utilization of rectification is applied. It may be called the rectifier bridge as shown in Figure 2(a) where the rectification occurs at all signs of the sinusoidal wave. It is a full wave rectification as shown in the figure where two rectified waves per cycle is better. It doubles the result value at the same time which gives an efficient concept for the rectification method.

A new concept for the rectification to get better results is to transform from 3 phase ( $3 \phi$ into the rectified wave (Three Phase Rectifier). This method is drawn in Figure 2(b) where the DC supply may be produced according to this process with higher cost. This allows getting more efficient output waveform where the average value will be a triple half instead the case of single phase. Thus, it maximizes the output wave form level as well as the final waveform approaches the DC waveform. This is clear from the drawings of Figure 2 in which the waveforms of the symmetrical $\mathbf{3} \phi$ are drawn in sequence. The average current will be the summation for all of them after rectification. Three Phase Rectifier Bridge is the most suitable rectification concept for the production of DC currents. It develops DC supply from AC circuits while this application is given in Figure 2(c). A $3 \phi$ bridge is highly effective more than all other circuits explained above. This effective value in the output is deduced due to the summation of the three waves of $\mathbf{3} \phi$.

\subsection{Converters}

The current state of power crisis has led inverters to become a part of every household, office and commercial 

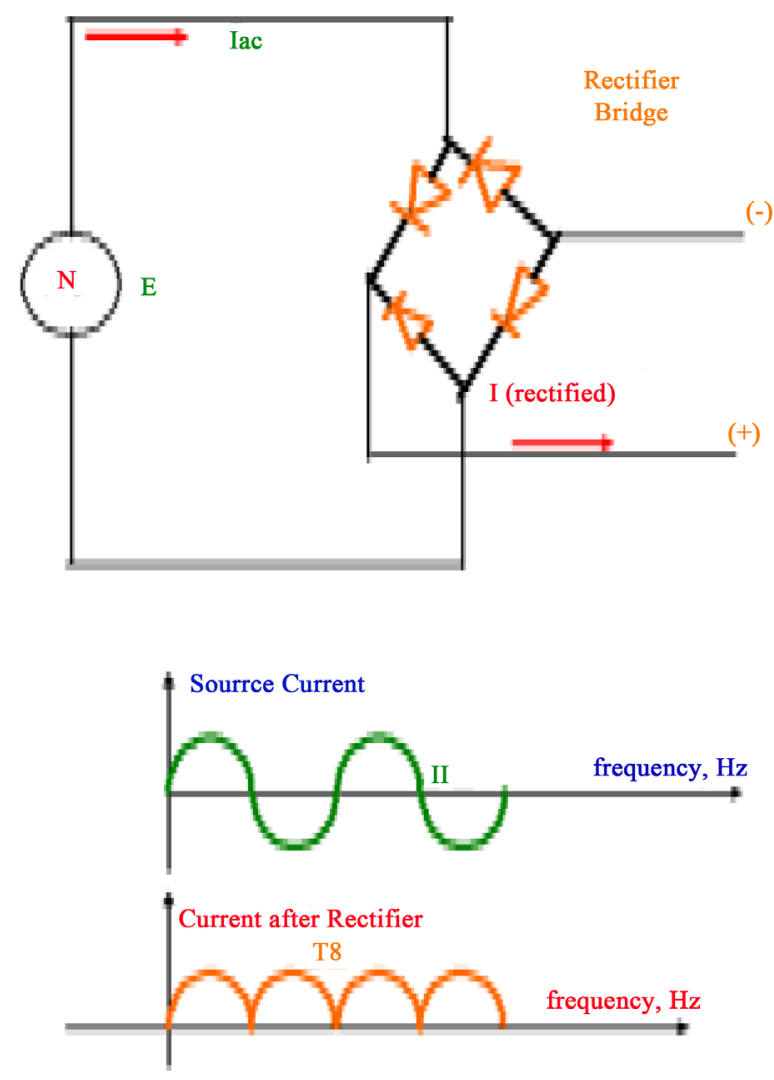

(a)

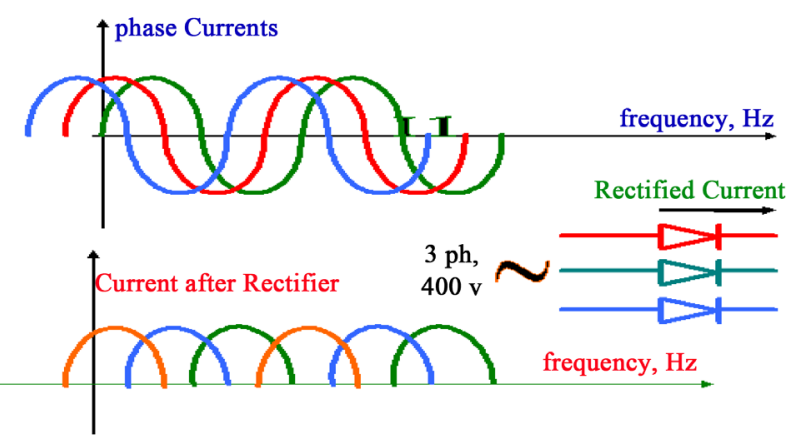

(b)
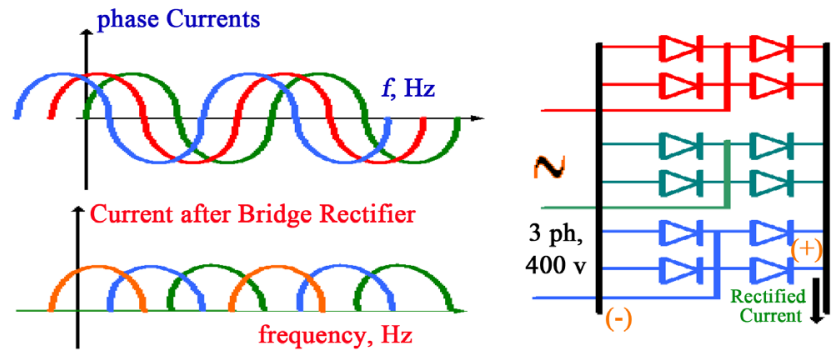

(c)

Figure 2. The rectification concepts in electric systems. (a) Single phase bridge, (b) Three phase rectifier, (c) Three phase bridge rectifier. 
complex because the need for power is increasing up every day. An inverter performs the function of converting DC into AC. Nowadays; inverters are popular and preferred more than generators because they require less attention. Also, they are silent during operation, rated at 200, 400, 600, and $800 \mathrm{kVA}$ and more above according to the requirements (see Figure 3). Apart from providing power backup inverters need protection to critical devices and instruments, during sudden power cuts, voltage power spikes, brown outs and frequency changes.

It is important to be noted that for any computer and sensitive digital machine, the uninterrupted power supply (UPS) systems, are in huge demand in offices, commercial spaces, editing studios, hospitals and households and others where their implementation can be available for both online and offline purposes. The UPS systems must outlive their warranty period and perform without any inconvenience to the clients. Inverter features are marked for highly efficient technology and silent operation. The operation must be suitable for high surge load capacity with a wide voltage range input where a protected battery (fused \& better reliability) would be included with normal/high charging options.

A main protection may be a vital such as over temperature and reverse phase protections while auto sense intelligent control smart charger may be now in use for quiet operation of AC motors (time delay relay), leading to a low harmonic distortion $(<3 \%)$. It will be suitable for providing alternate power source in corporate offices (including computer, scanner, printers, fax machines, etc.). It must be clear that, these inverters are provision for emergency and for portable power systems as well as all compressor based appliances (air conditioner, water pump, tread mills and other health equipments). Advanced design may present display indications (status \& fault) with battery state monitoring and the use of high tech permits the auto trickle mode (or multi stage battery charger) in addition to smart overload sense and short circuit protection.

\subsection{Uninterruptible Power Supply}

Mainly, an UPS protects critical data by supplying reliable, network-grade power in a traditional tower-style form factor. This UPS may be included with management software where this software provides IT administrators the comfort of safe system shutdown and advanced UPS management. Then, an intelligent and efficient network power protection from entry level to scaleable runtime can be attached. Phat (2012) [6] has studied the challenges of energy security to the industrialization where this way may be useful for the RE performance. Thus, servers, point-of-sale, routers, switches, hubs and other network devices can work ideally and safety. In addition to legendary reliability and manageability, Smart-UPS (normally standard value of $1 \mathrm{kVA}$ rating reaching $30 \mathrm{kVA}$ and more) have extremely high efficiency at low, medium and high load levels making them ideal for today's multi-core or virtualized servers that have varying load consumption. It is noted that, a compact UPS ensures an undisturbed power supply and backup for PC and peripherals where it may be integrated with external batteries. Normally, three replaceable battery backed UPS outlets, and one surge protection-only outlet differentiated by color with USB port may be applied.

\subsection{Batteries}

Generally, batteries are useful in a broad range of applications so that they are varied in a wide range either by the type or by the rating. They are also, used in many and many various applications so that they become a major tool in the modern life. The UPS depends mainly on the batteries where they are the vital component inside. These batteries are in use of absorptive glass mat separators. Therefore, maintenance is unnecessary during their life time while the use of high-purity calcium alloy will maximize the longevity of batteries. A battery is normally, further backed by the modern world technology where usually they are rechargeable, sturdy construction

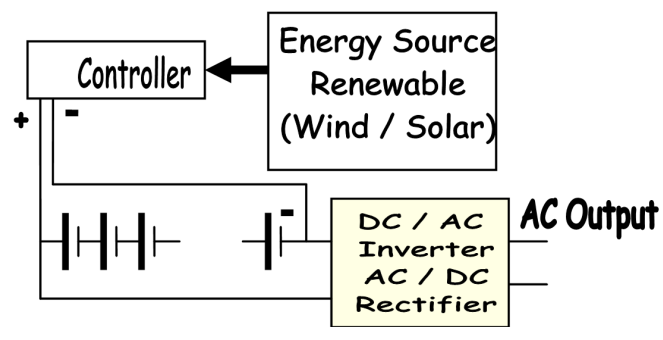

Figure 3. Converters in renewable energy systems. 
and compact design. They can undergo high number of charge/discharge cycles, have a good load performance, and have a long shelf life in any state of charge for a long range of temperatures. Thus, batteries require low maintenance and they are resistant to leakage. Consequentially, the combination of low antimony alloy and ceramic vent plug keeps the water addition requirement very low. A topping up frequency of once in 6 - 9 months can easily be achieved in normal operation while a special hybrid alloy system may be the best suited to withstand high temperatures.

Dual plate separation for double protection against shocks and vibrations would be considered besides Float/ Float guide to indicate electrolyte level position, which also acts as effective fume arrestors and enhancing safety too. All new alloy systems make the battery better suited for deep discharge although applications ensure extremely low water loss; and it has as increased reliability. Peak current term is usually applied to the continuous normal current although the electronic components can operate at larger currents than normal, only for $\boldsymbol{a}$ short time. This means that, the load can resist a high surge but for a short duration so that all units must have internal timers to reduce automatically the peak current to its normal after 2 - 12 seconds. Continuously, a recommended input voltage is usually $80 \%$ of the maximum rating of transistors inside. If the input voltage exceeds 1.25 times the recommended voltage, the unit will damaged. It should be noted that, models have automatic shut off to protect the unit if the input voltage is excessive. Also, as the input voltage is increased, eventually the unit will violently fail.

Bad output voltage may be appeared if harmonics are superimposed on the DC voltage causing ripples. AC voltage is riding on top of DC voltage at the output of a unit while it is sinusoidal and is expressed in peak of RMS. On the other side, the operating temperature range for all these components is normally considered in the range $\left(-10^{\circ} \mathrm{C}\right.$ up to $\left.+60^{\circ} \mathrm{C}\right)$. Most standards are specified for input voltages $12 \mathrm{~V}, 18 \mathrm{~V}$, and $24 \mathrm{~V}$ while output voltage will be 24,36 , and $48 \mathrm{~V}$, respectively. The average power is $200-800 \mathrm{~W}$ with a little varied efficiency as (94\% - 97\%). The charging voltage for a battery should be above the nominal by $2 \mathrm{~V}$ for a charging current of $4 \mathrm{~mA}$. The real output power of a battery depends on the output power of solar panel. The construction of wind project normally take about a year and so it will create around hundreds jobs during the construction phase and tens full-time positions when it becomes operational. This is the way for the activation of commercial market for all necessary industries so that it should be considered for the economic evaluation in such cases.

\subsection{Geothermal Electricity}

Heat from earth (geothermal energy GE) originates from deep within earth producing minimal emissions. It heats water seeped into underground reservoirs $\left(225^{\circ} \mathrm{F}-600^{\circ} \mathrm{F}\right)$ which would be tapped for a variety of applications, depending on water temperature. GE is more cost-effective and competitive with fossil fuels. It has been used in USA to generate electricity since 1960 although there are currently various types of GE plants. The nontraditional resources are valuable for $\mathbf{R E}$ recently because there are many crises has been occurred during the last century. Plants use dry steam from underground wells to rotate a turbine, for generator activation. This type of resources may be rarely viewed around the world. Flash steam plants are the familiar type of GE, depending on the use of water wells at more than $360^{\circ} \mathrm{F}$. Thus, the solar radiation is a general term for electromagnetic radiations emitted by sun where it can be captured and turned into useful forms of energy on the basis of a variety of technologies. However, the feasibility and economics of these technologies at a specific location depends on the available solar resource with time and place. The solar radiation factors are: (geographic location, time of day, season, local landscape, and local weather).

It is a fact that, the sun strikes the ground surface at different angles, ranging from $0^{\circ}$ (just above the horizon) to $90^{\circ}$ (directly overhead) because the earth is round. Therefore, the frigid Polar Regions never get a high sun due to the tilted axis of rotation; these areas receive no sun at all during part of the year. When sun's rays are vertical, Earth's surface gets all the energy possible at a certain place. Since the earth revolves around sun in an elliptical orbit, it becomes closer to the sun (earth's surface receives a little more solar energy) during only two parts annually. The earth is nearer to the sun when it is summer in each year in the southern hemisphere, and similarly, winter in the northern hemisphere. Geographically, days and nights are both exactly 12 hours long on the equinoxes where this is occurred periodically annually on around March 23 and September 22. Countries such as USA, Nigeria and India, which lie in the middle latitudes, receive more solar energy in summer because not only days are longer, but also the sun is nearly overhead. On the other side, the sun's rays are far more slanted during the shorter days of the winter months. 
Emerging Energy can be developed and delivered from oil and natural gas, which will remain the world's predominant sources of energy for many decades coming. Sequentially with the growing demand of developing economies, we will need every energy source available, including $\mathbf{R E}$ but experience in finding, producing and delivering energy must lead to a commercial-scale development of RE. A pragmatic approach may be introduced as geothermal, advanced bio-fuels, solar and energy efficiency technologies. Simultaneously, internal research must be conducted and collaborated with governments, businesses and academia in researching and developing alternative $\mathbf{R E}$ sources. Then through these partnerships, information would be shared for technology advancement as world looks at providing $\mathbf{R E}$ for future generations.

Bio-fuels may appear as the focus areas in a lot of places on the universe for future. This may be defined into three generations while a first traditional generation biofuels would be derived from edible sugars and starches. Such type may limit our choice of raw materials to those that do not materially impact food or feed supplies. The role depends on many factors, including advances in future technology, public acceptance and economic viability. So, all countries must encourage clean technology innovation and small-business development while we would bring emerging technologies together with companies around the world to deliver the world's energy today and in future too.

\section{Economic Approach}

Nowadays, there are many directions or categories which play a role in the utilization of RE. From the economic point of view, the most important categories are energy type, output style and utilization concept. These three items may be the principle way to differentiate where each of them has itself characteristics as explained above. So, the first and second categories will be taken off so that the third one will be accounted in the present research besides the economic base as addition for the principle categories. This means that, all these four categories and others play a vital role in the system as a whole. The interested item of energy utilization may not depend on RE sector because it is the distribution networks. Therefore, a new view for the electric power generation must be innovated since $\mathbf{R E}$ is expensive to get where the fourth added item can push in advance quickly. This would be based on a principle strategy in the cheaper direction for the production of $\mathbf{R E}$ so that the opposite direction may aid in the solution. So, this section presents a support strategy in a new suite for possible applications however it may depend on the power distribution system plus the proposed here economic principle. In other words, $\mathbf{R E}$ efforts must be continued as speedy as besides the proposed here idea. Thus, a new addition for the present nominal distribution network could be a helpful point inside the system of support for RE although it may be a technical slowing point. Thus technically, the proposed strategy base can be concluded according to a basic simple mathematical analysis given now.

From the economic point of view, the target of the present paper for the RE support can be formulated on the four branches, two are the technical section of work and the other two are for the economic analysis. Technical section consists of both Electrical concept and Industrial category while the economic section is divided into Banking policy and Marketing activation. The first branch (technical support) may be considered as the door for the next branches because it gives the details of all components to be priced in the proposed model. It may take a large area of explanation of the subject but this may go to the vital points determining the most suitable installation at the desired lowest cost. Similarly, the second branch (industrial category) can be joined to the technical evaluation in spite of its basic relation to the economic strategy. So, both technical parts of the proposed method can be merged together but a simple illustration may be tailored.

\subsection{Distribution Networks}

Distribution network consists of all terminals of the united power system as a whole and the consumer's loads however these loads may be in different shapes and types. Then, the type of distribution systems could be defined as AC or DC distribution networks. Therefore, AC systems are preferred because it a continuous connection for AC transmission due to advantages as: [cheaper method for the generation of electrical power, simple regulation for the voltage through power transformers (either ON load or OFF load tap changers) while the voltage control is easy for the distribution networks, good economic solution due to the application of $\mathbf{3} \phi$ systems and (easy/cheaper) maintenance for the system]. On the other side, advantages of both transmission and distribution DC networks can be abstracted as follows:

1) The displacement angle will be disappeared completely since the reactive impedance is absent, no capa- 
citance or even inductance for the conductors (wires) and so no reactive loss.

2) Reduction of the interference between AC and DC circuits.

3) Conductor skin effect is absent and then, the rating of a wire must be raised.

4) Less corona loss for transmission systems relative to the corresponding AC networks.

5) Voltage drop along a cable will be less due to the zero inductance effect in DC circuits.

6) There is no need for the stabilization in the case of long lines in transmission systems.

7) The charging current is zero relative to $\mathbf{A C}$ circuits so that the loss at no load conditions will be zero.

8) It is a cheaper system because it needs only 2 conductors/circuit or even one conductor only plus the earth such as the electrical networks of cars. This leads to a saving in the expensive materials (copper conductor).

9) The insulation potential gradient is less relative to AC by $1: \sqrt{2}$ ratio so that the cables will be cheaper too.

10) Cheaper implementation for the underground cables at the same rating.

Tabulation for the difference and comparison between over head wires and underground cables is listed in Table 1 where specific important items are illuminated.

It should be noted that, the effect of nominal operating voltage for feeders in DC distribution networks is shown in Figure 4(a) where the conductor material is saved. In this concern, the current density $\boldsymbol{J}(\boldsymbol{t})$ is a function of both conductor diameter $d$ (or area $A$ ) and the continuous time $t$ of loading a current $I$ as shown in Figure 4(a) according to the general mathematical time function.

$$
J(t)=\frac{I(t)}{A}
$$

Thus, all parameters are a function of the applied time so that DC utilization reduces the conductor size of feeders and distributors for a constant power $(P=V I)$. If we have a multi $n$ feeder system, the definition of current $I$ and voltage $V$ for each distributor of a cross sectional area $\boldsymbol{A}$ as

$$
[V n, I n, A n]=\left[(n \times V),\left(\frac{I}{n}\right),\left(\frac{A}{n}\right)\right] .
$$

In the case of DC systems as shown in Figure 4(b) where the single line diagram of a distributor is given, we have for the voltage drop $v$ across a feeder of resistance $R$ as $v$ ratio to current $(R=v / I)$. With increasing the

Table 1. Comparison between over head wires and underground cables.

\begin{tabular}{ccc}
\hline Item/item & Underground cables & Over head wires \\
\hline Public safety/faults \& failures & Safer/better & Not safe/higher \\
Capital cost/running cost & Expensive/very low & Cheap/high \\
Flexibility/appearance & New cell for a cable /invisible & Flexible/visual view \\
Operating voltage/voltage drop & Less than $11 \mathrm{kV} / \mathrm{low}$ & Any higher/higher \\
Damage strokes/HF interference & No lighting \& thunders $/$ non & Affected possibility/possible \\
Jointing/fault location & Difficult/difficult & Simple/cheaper \\
Surge effect/charging current & Smooth due to sheath/higher & Direct effect/only for long lines \\
Maintenance & Expensive & Easy \\
\hline
\end{tabular}

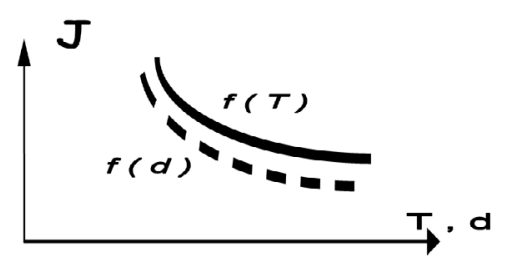

(a)

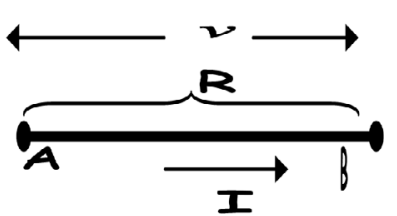

(b)

Figure 4. The effect of conductor dimension. (a) Current density dependency, (b) Voltage drop with conductor length. 
voltage drop $n$ times, the current will be decreased by the same ratio so that the resultant resistance $R_{n}$ will be

$$
R_{n}=n \times \frac{v}{\left(\frac{I}{n}\right)}=n^{2} \times R .
$$

Therefore, DC systems reduce the area for required conductor wires while in another view it increases the transmission efficiency $\eta$ as a positive addition for DC systems. This may be appeared with the known mathematical expressions for the sending end voltage $V$ with a current $I$ and resistance $R$. So, the efficiency $\eta$ would be derived as

$$
\eta=\frac{\text { Output }}{\text { Input }}=I \frac{V}{[I(V+2 I R)]}=\frac{V}{(V+2 I \times R)}=1-\left[2 I \frac{R}{V+2 I R}\right] .
$$

With the rise of $n V$, the current for the same power will be $(I / n)$ while the resistance for each cable is $n R$. Then, the efficiency $\eta$ may be formulated:

$$
\eta=\frac{\left(\frac{I}{n}\right) n V}{\left[\frac{I}{n}(n V+2 I R)\right]}=\frac{V}{V+2 I \times \frac{R}{n}}=1-\left[2 I \times \frac{R}{n V+2 I R}\right] .
$$

Whatever, DC distribution systems may be classified in a major sequence as: (2 wire, 2 wire DC with earthed midpoint and 3 wire $\mathbf{D C}$ systems). These three systems can be economically compared with AC systems where the last are varied according to the number of phases. Single phase systems may be either single phase 2 wire, or single phase 2 wire with earthed midpoint or single phase 3 wire AC systems while $2 \phi$ systems can be $2 \phi$, 4 wire or $2 \phi, 3$ wire AC systems. Also, usual $3 \phi$ systems have either 3 wire or 4 wire AC systems.

A brief comparison, mathematically, for the economic saving can be illustrated as given directly in Table 2 . The comparison is done for the conductor cost at same power and operating voltage while the economic study appears to be the target. Generally, the circuit diagram for all given distribution systems are drawn in Figure 5(a) and Figure 5(b) as currents and voltages are illustrated on each circuit, individually. All cases are given in serial numbers as a subscript for current and maximum voltage $V_{m}$ while RMS voltage is defined $\left(V_{R M S}=V_{m} / \sqrt{6}\right)$. The comparison has been done for the unity system where the value $\mathbf{1}$ represents the base reference for calculations.

Whatever, the DC circuits have no displacement while the AC systems have a displacement angle of $\phi$. So, the dependency of the economic saving is sharply dependent on the power factor (p.f.) which is defined mathematically as $\cos \phi$. It should be remarked that, the best of all systems driven in Table 2 is the double wire DC with earthed midpoint systems because the ratio is $1 / 4$. It is less than unity where there is no displacement angle. It is needed to say that, these systems are explained before in the previous chapters when the dynamic loads were studied. The last circuit for $\mathbf{3} \phi, \mathbf{4} \mathbf{w}$, AC systems is a real network for distribution systems where it is normally unbalanced. So, the neutral current is always high although $\mathbf{3} \phi$, $3 \mathbf{w}$ networks are balanced mostly for large industrial loads. Consequentially, the current $I$ will be expressed referring to power $P$ by

$$
I=\frac{P}{\left[3\left(\frac{V_{m}}{\sqrt{6}}\right) \cos \phi\right]}=\frac{\sqrt{6} P}{\left[3 V_{m} \cos \phi\right]} .
$$

\subsection{Design Strategy}

Nowadays, the global electricity sector and its customers are faced with a number of challenges that are unparalleled since the advent of widespread electrification. Challenges including climate change, escalating energy prices, energy security and energy efficiency are converging to drive fundamental change in the way energy is produced, delivered and utilized. The electricity system of the future must produce and distribute electricity that is reliable, affordable and clean. To accomplish these goals, both the electricity grid and the existing regulatory system must be smarter (Hidayatullah et al., 2011) [15].

The design of a distribution wiring would be based on the economic class since the price of any item must be 
Table 2. The comparison between all AC and DC distribution systems.

\begin{tabular}{|c|c|c|c|c|}
\hline Current & Phases & Wiring system & Overhead lines & Cables \\
\hline \multirow{3}{*}{ DC } & & $2 w$ & 1 & 1 \\
\hline & & $2 \mathrm{w}$, earthed midpoint & $1 / 4$ & 1 \\
\hline & & $3 w$ & 0.3125 & 1.25 \\
\hline \multirow{7}{*}{$\mathrm{AC}$} & \multirow{3}{*}{1} & $2 w$ & $2 / \cos ^{2} \phi$ & $2 / \cos ^{2} \phi$ \\
\hline & & $2 \mathrm{w}$, earthed midpoint & $0.5 / \cos ^{2} \phi$ & $2 / \cos \phi$ \\
\hline & & $3 w$ & $0.625 / \cos ^{2} \phi$ & $2.5 / \cos ^{2} \phi$ \\
\hline & \multirow{2}{*}{2} & $4 w$ & $0.5 / \cos ^{2} \phi$ & $2 / \cos ^{2} \phi$ \\
\hline & & $3 w$ & $1.457 / \cos ^{2} \phi$ & $2.914 / \cos ^{2} \phi$ \\
\hline & \multirow{2}{*}{3} & $3 w$ & $0.5 / \cos ^{2} \phi$ & $1.5 / \cos ^{2} \phi$ \\
\hline & & $4 \mathrm{w}$ & $0.583 / \cos ^{2} \phi$ & $1.75 / \cos ^{2} \phi$ \\
\hline
\end{tabular}
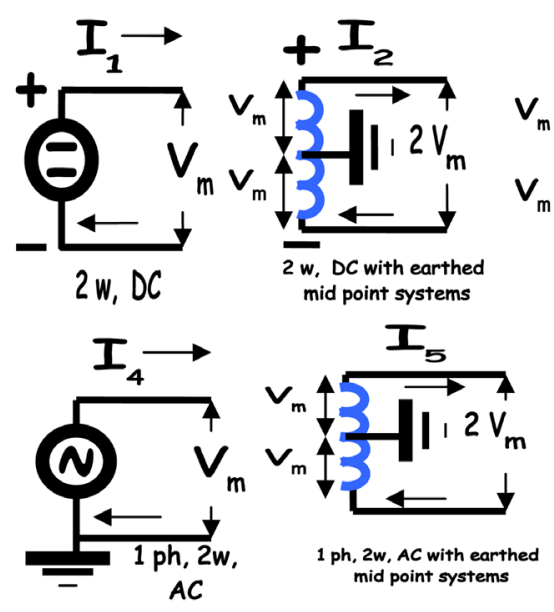

(a)
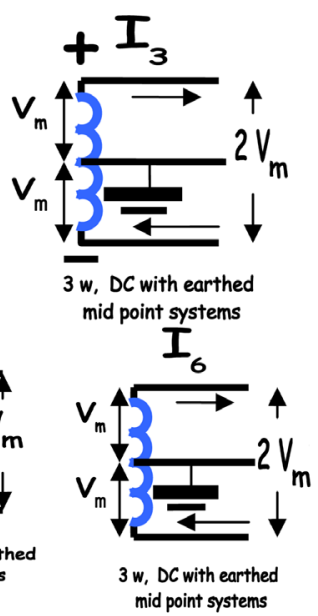

mid point rystems

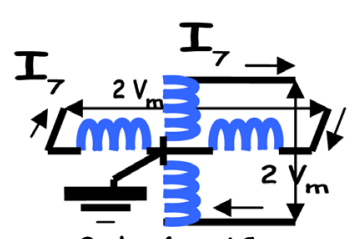

$2 \mathrm{ph}, 4 \mathrm{w}, \mathrm{AC}$

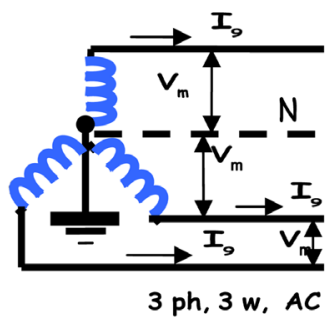

$3 \mathrm{ph}, 3 \mathrm{w}, \mathrm{AC}$

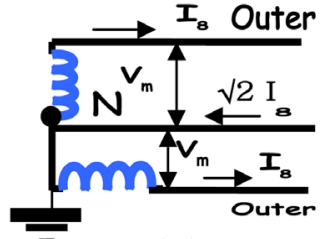

Double phase, 3 w, AC

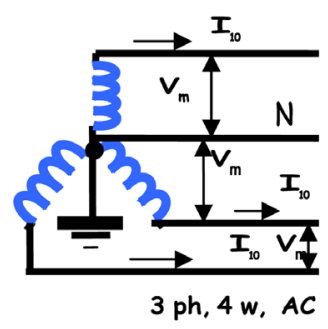

(b)

Figure 5. The distribution systems. (a) DC systems, (b) AC systems.

considered for. So, the selection for voltage and kind of the system could be important since there are usually a lot of standard values can be chosen. This process should be accounted in order to get the energy cost as minimum as possible. Also, the effective engineering factor for such evaluation may be illuminated by the efficiency of the network although it may be partitioned into a lot of sections to evaluate the efficiency. In the above style of the distribution networks, the basic items for advantages can be also introduced. Since we need to minimize the current carrying capacity, the $\mathbf{H V}$ tendency will be important. Otherwise, the efficiency $\boldsymbol{\eta}$ in the transmitted power would be the base factor for comparison as it can be expressed in the form

$$
\eta=\frac{\text { output }}{\text { input }}=\frac{\text { output }}{[\text { output }+ \text { cableloss }]}=\frac{\text { output }}{\left[\text { output }+I^{2} R\right]} .
$$

This formula determines the actual term which may be the major factor so that the loss value should be minimum. So, the resistance of a cable or a line could be minimized since the conductor material conductivity is very high. Then, the material besides the loss will direct the designer to the effective selection. The main advantages for AC transmission should be named as: (simple voltage regulation, low cost, reduction of conductor size, effective transmission (high efficiency), current reduction, and very long lengths would be approved and low voltage drop across lines). Contrary, disadvantages can be addressed as: (the present of corona loss with $\mathbf{H V}$, high requirements for the insulation, the power factor modification can be handled, and large spacing between phases will be needed). 


\subsection{Conductor}

Starting from the material classifications according to the properties in general (chemical, magnetic, electrical and mechanical), electrical properties may lead to the selection of a suitable conductor (cable) because the conductor price depends on the type selected in addition to the type of accessories and auxiliaries of installation of a distribution network. There a lot of shapes for the conductors such as: (wires, insulation coated wires, cables, circular wires, rectangular or square bars, angles, channels, flat strips, and many others). The electrical properties of conductor materials can be analyzed shortly.

A material resistivity $\rho$ in $\Omega \cdot \mathrm{m}[\rho=(R \times l) / A]$, having a length $l$, sectional area $A$ and resistance $R$, causes a power loss in a circuit. Otherwise, the resistivity depends on some factors as: (alloying: the resistivity increases with the alloy content, aging, mechanical characteristics, heat accumulation inside). Contrary, the conductivity of a material $\left(\Omega^{-1} \cdot \mathrm{m}^{-1}\right)$ is the reciprocal of the resistivity $\rho$ while super conductivity is appeared in the practical applications (since some metals and compounds can lose their electric resistance abruptly before the absolute zero temperature). This means a circuit without any resistance (super conductor) whatever; the super conductivity temperature is varied from a metal to another. However, the resistance of AC circuit is a part of the impedance $\mathbf{Z}$ (Resistance, Inductance, Capacitance and Leakance). The resistance is varied either with temperature or with the type of applied current because the DC resistance is always less than the corresponding AC value. Dielectric strength means resistance of a material for the voltage rise withstand where the conductors have a very low resistance. Insulators must withstand even with $\mathbf{H V}$ level so that they can be used as an isolation medium between the conductors (carrying currents) and the earthed land or even earthed walls (zero potential). The resistance of a conductor is low but it is high for insulators.

Since a current produces a heat excess in the conductor, whose dimensions should be varied accordingly. So, its resistance will be changed during the current passing through and consequentially, the new resistance must be inserted in the computation of the factors of this circuit. Thus, the temperature coefficient $\alpha_{T}$ of a resistance controls such effect where it is defined theoretically as:

$$
\alpha_{T}=\frac{\left[\rho_{1}-\rho_{2}\right]}{\rho_{2}}=\frac{1}{\left[T_{1}-T_{2}\right]} .
$$

This equation can be reformulated, due to temperature (in $\mathrm{K}$ ) variation, for the resistance $R$ calculation as:

$$
R_{1}=R_{2}\left\{1+\left[\frac{\alpha T}{\left(T_{1}-T_{2}\right)}\right]\right\} .
$$

Thus, Table 3 lists the variation characteristics for the most known conductors.

There are a lot of factors for this item although more new factors may be introduced in future. The concerned properties may be defined as: (electro physical, electro chemical, electro mechanical and electromagnetic). Firstly, the major requirement for a conductor can be: [high electric conductivity (low resistivity), easy availability, low specific gravity, high tensile strength, low cost and non brittle] and so, its price will be affected. It should be mentioned that, there is no pure material can meet these entire requirements so that a merging for two or more (alloy) may reach the goal. Acircular stranded (diameter $d$ each) conductor, with outer diameter $D$ $[D=d(2 n+1)]$ as a function of the number of layers $n$, faces the required tensile stress where stranding shall be in adjacent layers and the total number of strands $N$ in a conductor is computed as $[N=3 n(n-1)+1]$.

Since the conductor resistance plays a great role not only in a cable power loss but also in the voltage drop across its terminals, a brief summary for the most important factors for these materials should be a step towards the best design for the wiring scheme. Finally, DC systems appear to be the most economic so that the necessary strategy is to direct the distribution networks towards DC systems. This may be implemented as a replacement

Table 3. The variation characteristics of resistivity $(\Omega \cdot \mathrm{m})$ for some conductors at $20^{\circ} \mathrm{C}$.

\begin{tabular}{ccccccccc} 
Material & $\rho\left(10^{-10}\right)$ & $\alpha\left(10^{-4}\right)$ & Material & $\rho\left(10^{-10}\right)$ & $\alpha\left(10^{-4}\right)$ & Material & $\rho\left(10^{-10}\right)$ & $\alpha\left(10^{-4}\right)$ \\
\hline Aluminum & 2.69 & 40.3 & Nickel & 10.5 & 40 & Lead & 21 & 41 \\
Annealed cu. & 1.72 & 39 & Silver & 1.6 & 40 & Iron & 9.8 & 65 \\
Tungsten & 5.5 & 50 & Tin & 11.5 & 46 & & & \\
\hline
\end{tabular}


or addition and extensions for the present connections. Otherwise the running cost; for a cable or distributor depends on the type of conductor material so that these materials would be given. This idea is a major support for RE because this will take action in the direction of facility towards it. This means that the application of DC distribution systems must give a bonus point for $\mathbf{R E}$ so that the converter stations attached to WF or solar sources may not be required. It is another new strategy to improve the performance of $\mathbf{R E}$ applications in spite of the trying of Saleh and Eskandar (2011) [16] to define the sizing of converters for machine drives. The support would be from the electricity companies to go towards the proposed idea in addition to the industry field to manufacture equipments and devices for DC networks. The effort of Governments as well as electric authorities and companies would be increased as well as the industry sector that may direct factories to manufacture a lot of appliances for DC implementation.

\subsection{Industrial Category}

The industrial category in this concept plays a major role in the costing process since the industrialization of most components required either for the $\mathbf{R E}$ generation or for the DC appliances (devices, lamps, instruments, tools, house cooking machine, etc.) can be manufactured locally. This means that the labor quantity must be increased and consequentially, the market cycling may be improved beside the economic benefits. Also, the DC products market will be more active so that a dynamic growth in the GDP can be seen. The industrial principle would be encouraged by the government because the policy of the government can direct the financial support towards the simple and small industries not only for the official sector but also for the private one. So, small investors will be bold to entry this type of industries. Contrary, the already required industries would be advanced in forward to modify and get the best products to serve the $\mathbf{R E}$ industries. The benefits of such policy could be reflected on the marketing growth in each country and so, the macroeconomic may be raised. Different industries must be affected by the policy of industrialization because the small industry may depend on others far industries.

The industry category may be divided into two branches as the direct energy tools and devices branch and the second one which may be another type of industry. The first division is still expensive because of the little number of renewable energy consumers. So, a credit system must be built in order to encourage customers to go towards RE style. The present systems in some countries can't active the targ et al. though it succeeded in many developed countries. The activation of a new more reliable system can be achieved through the technical view explained above where the car field industries could be a good market for the utilization. The second division may be represents as all industries that serve the production of tools and devices and all accessories of $\mathbf{R E}$ components.

Finally, the technical part of analysis may be now clear and simple for the economic reading evaluation so that the second part as defined above will contain the two sections of both Banking policies and Marketing activation as well as the government support for this branch. This can be studied in more details as given below.

\section{Cost Analysis}

Basically, a linear cost dependency should be assumed as well as the average cost will be considered for simplicity. The combination between RE sources and traditional AC power network is drawn in Figure 6 although different internal parts would be differentiated for the cost study. The given above analysis for the electrical

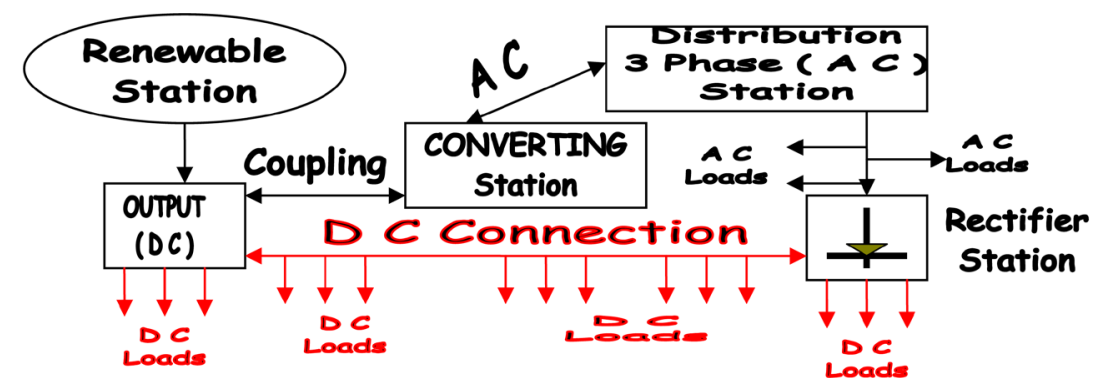

Figure 6. The block scheme for coupling between renewable energy generation and electric grid. 
connections and components is a vital item in the economic investigation because all these elements and others should be evaluated. This means that, each element must be priced for an exact costing although the simple global for a sum of them may be priced as a block together in the present research model. The proposed model is a global indicator model in order to prove the quality of the suggested principle for all countries around the world. The aimed support may be built on the two basic economic fields as banking policy as well as the marketing activation since the unidirectional concept for could not stand against the opposite force of expensive energy. The banking policy can overcome the present problem through the facilities requirements for small investors plus bonus credits so that banking leaders should face the item and go on without any doubt. This may be a regulation dependent but brave is very needed to cross. The second category (marketing activation) is a simple so that all investors and industry men will welcome for such strategy. However, marketing activation represents a target for all steps of the system of production, marketing and utilization while the economic activity will be better due to the proposed marketing dynamics.

Since the applications of $\mathbf{R E}$ are mainly related to the far points of population, the population (residents) must be a vital factor in the economic effect on the RE appearance on the surface. Wanxin, W., Zequn, G. (2013) [17] investigated this subject using the MATLAB programming with a growth model for the population growth in China. They studied the capital-labor ratio besides the population growth situation. However, Pekár et al. (2013) [18] applied the maximizing of Omega function to select the portfolio while economic impact for the using the waste as a production input through the blue economic has been proposed by Varga et al. (2013) [19]. This seems to be analogue to the $\mathbf{R E}$ support policy.

A per unit system for the economic evaluation would be introduced where the ratio of average cost for the needed parts for the two cases: AC and AC/DC distribution systems. Therefore, relative cost for the added technical parts would be estimated in order to ensure the validity of the proposed AC/DC distribution system. So, a major price value of $\mathbf{X}$ would be proposed while all approximate prices of parts inside will be measured. This price could be different from a country to another so that the presented analysis must be suitable for all. The DC loads would be proposed as $\mathbf{1 2} \mathbf{V}$ loads since the market has such requirements such as lamps, machines, tools, etc. This means that the market of car auxiliaries and some spare parts will be refreshed well as well as the cost analysis may be modified (less price); than any other voltage level. Table 4 lists various global prices of components in this investigation when the average approximate value for the price is presented. It is important to indicate that, the use of $\mathbf{D C}$ application is more safety than the AC system although the heavy power consumption will not. Also, the most used rated power for loads may be considered in order to simplify the mathematical analysis. The given initial data may be summarized in Table 5 where all values are indicated as referred to the

\begin{tabular}{|c|c|c|c|c|c|c|c|c|}
\hline Place & Component & Quantity & $\begin{array}{l}220 \mathrm{~V} \\
\text { price }\end{array}$ & $\begin{array}{l}12 \mathrm{~V} \\
\text { price }\end{array}$ & Component & Quantity & $\begin{array}{l}220 \mathrm{~V} \\
\text { price }\end{array}$ & $\begin{array}{l}12 \mathrm{~V} \\
\text { price }\end{array}$ \\
\hline \multirow{6}{*}{ Loads } & Lamp & 100 & $6 X$ & $2 X$ & Lamp holder & 100 & $4 X$ & $\mathbf{X}$ \\
\hline & Wire unit & $10 \mathrm{~m}$ & $2 x$ & $\mathbf{X}$ & Panel board & 1 & $200 X$ & $20 X$ \\
\hline & Rectifier & 1 & $100 \mathrm{X}$ & $\mathbf{0 X}$ & Signal system & 1 & $5 X$ & $5 X$ \\
\hline & Circuit breaker & 10 & $10 \mathrm{X}$ & $2 x$ & Switch & 10 & $3 x$ & $3 x$ \\
\hline & Fuse & 10 & $5 X$ & $\mathbf{X}$ & Relay & 10 & $30 \mathrm{X}$ & $30 \mathrm{X}$ \\
\hline & Earthing & 1 & $20 \mathrm{X}$ & $\mathbf{0 X}$ & Metering & 1 & $40 \mathrm{X}$ & $40 \mathrm{X}$ \\
\hline \multirow{4}{*}{ Stations } & Converter & 1 & $1000 \mathrm{X}$ & $\mathbf{0 X}$ & Rectifier & 6 & $100 X$ & $\mathbf{0 X}$ \\
\hline & $\begin{array}{c}\text { Internal } \\
\text { connections }\end{array}$ & 3 & $100 \mathrm{X}$ & $0 \mathrm{X}$ & $\begin{array}{c}\text { External } \\
\text { connections }\end{array}$ & 3 & $200 X$ & $\mathbf{0 X}$ \\
\hline & Control room & 1 & $300 \mathrm{X}$ & $250 X$ & Control circuits & 1 & $120 X$ & $50 X$ \\
\hline & $\begin{array}{l}\text { Protection } \\
\text { schemes }\end{array}$ & 1 & $200 X$ & $150 X$ & Signaling & 1 & $30 \mathrm{X}$ & $30 \mathrm{X}$ \\
\hline \multirow[b]{2}{*}{ Coupling } & Wires & $100 \mathrm{~m}$ & $15 X$ & $\mathbf{0 X}$ & Towers & 2 & $200 X$ & $\mathbf{0 X}$ \\
\hline & $\begin{array}{l}\text { Protection } \\
\text { schemes }\end{array}$ & 1 & $100 \mathrm{X}$ & $\mathbf{0 X}$ & Signaling & 1 & $20 X$ & $\mathbf{0 X}$ \\
\hline Maintenance & Major & 1 & $1000 \mathrm{X}$ & $100 X$ & routine & 2 & $100 X$ & $5 X$ \\
\hline
\end{tabular}


Table 5. The collected data for the cost of a chosen distribution supply.

\begin{tabular}{cccccc}
\hline System & Loads & Stations & Coupling & Maintenance & Total \\
\hline 220 V (AC) & 1865 & 3150 & 2020 & 1200 & 8235 \\
12 V (DC) & 735 & 480 & 0 & 105 & 1320 \\
\hline
\end{tabular}

basic price $\mathbf{X}$. However, the banking support for such tendency may be a positive value in spite of the risk evaluation for such cases.

Broll et al. (2011) [20] concluded that the economic environment for financial institutions has become increasingly risky and advised institutions to find ways to manage risk of which one of the most important forms is credit risk. They depended on the mean-variance (mean-standard deviation) approach to examine a banking firm investing in risky assets and hedging opportunities.

This means that the cost of the proposed distribution system is $1320 \mathrm{X}$ units relative to $8235 \mathrm{X}$ units in the case of pure AC networks. So, a mean saving of $[(8235-1320) / 8235=6915 / 8235=83.97 \%]$ may be occurred although this approximate value can be varied from a country to another. Also, this saving depends on the time of application where the marketing process is always changeable with time. This is a simple calibration for the proposed tendency so that it may help well in the macroeconomics development due to the inrush pushing for the small industries related in each country. The future work should be stressed on this scale as the primary results give a good indication.

Contrary, banking investment in the field of mobile industry is in a competitive condition all the time because of the high quick profit (Baranes and Vnong, 2011) [21]. Thus, a great attention should be faced by banks around to the financial support for the $\mathbf{R E}$ industries in each country where the $\mathbf{R E}$ generation can be utilized.

\section{Conclusions}

From the above analysis, it is concluded that:

- New strategy for the supporting of renewable energy advancement would be inserted in the international policy.

- The proposed strategy directs the support operation to the application terminals in all related fields.

- The DC distribution networks should be appeared in a wide scale in the world around.

- On the basis of economy requirements, the industry of appliance devices, lamps and equipments as well as other instruments must be produced in the scale of mass production in order to cover the future increase of their use.

- The international marketing of the DC appliances and even devices as well as instruments, especially for the car spare parts markets, will grow around the world due to the tendency for the use of DC supply as a terminal in distribution electric networks.

- The banking support for the RE applications and all related industries is required in spite of the risk involved.

\section{References}

[1] Feng, Y.X., Goerner, K., Cheng, G. and Wang, J. (2011) Influence of Catalyst and Temperature on Gasification Performance by Externally Heated Gasifier. Smart Grid and Renewable Energy, 2, 177-183. http://dx.doi.org/10.4236/sgre.2011.23021

[2] Zaki, G.M., Jassim, R.K. and Alhazmy, M.M. (2011) Energy, Energy and Thermo Economics Analysis of Water Chiller Cooler for Gas Turbines Intake Air Cooling. Smart Grid and Renewable Energy, 2, 190-205. http://dx.doi.org/10.4236/sgre.2011.23023

[3] Fernald, K.D.S., Weenen, T.C., Sibley, K.J. and Claassen, E. (2013) Limits of Biotechnological Innovation. Technology and Investment, 4, 145-212. http://dx.doi.org/10.4236/ti.2013.43020

[4] Gao, Y. and Razak bin Chik, A. (2013) A Multiple Regression Analysis on Influencing Factors of Urban Services Growth in China. Technology and Investment, 4, 1-82. http://dx.doi.org/10.4236/ti.2013.41B001

[5] Tang, S. (2011) Traffic Modeling of a Finite-Source Power Line Communication Network. Smart Grid and Renewable Energy, 2, 261-270. http://dx.doi.org/10.4236/sgre.2011.23029

[6] Phat, N.T. (2012) Challenges of Energy Security to the Industrialization and Sustainable Development in Vietnam. 
Technology and Investment, 3, 129-202. http://dx.doi.org/10.4236/ti.2012.33024

[7] Arslan, B. and Ozturan, M. (2011) The Path to Information Technology Business Value: Case of Turkey. Technology and Investment, 2, 52-63. http://dx.doi.org/10.4236/ti.2011.21007

[8] Khan, S. and Islam, A. (2011) Performance Analysis of Solar Water Heater. Smart Grid and Renewable Energy, 2, 396-398. http://dx.doi.org/10.4236/sgre.2011.24045

[9] Derouiche, H., et al. (2011) The Effect of Energy Levels of the Electron Acceptor Materials Organic Photovoltaic Cells. Smart Grid and Renewable Energy, 2, 278-281. http://dx.doi.org/10.4236/sgre.2011.23031

[10] Mandal, K.K. and Chakraborty, N. (2011) Optimal Scheduling of Cascaded Hydrothermal Systems Using a New Improved Particle Swarm Optimization Technique. Smart Grid and Renewable Energy, 2, 282-292. http://dx.doi.org/10.4236/sgre.2011.23032

[11] Seacord, R.C., Dorman, W., McCurtey, J., Miller, P., Stoddard, R., Svoboda, D. and Welch, J. (2010) Source Code Analysis Laboratory (SCALe) for Energy Delivery Systems.

[12] Dwivedi, G., Jain, S. and Pal Sharma, M. (2011) Pongamia as a Source of Biodiesel in India. Smart Grid and Renewable Energy, 2, 184-189. http://dx.doi.org/10.4236/sgre.2011.23022

[13] Gomes, J.F.P. and Cardoso, P.M. (2011) Notice on a Case Study on the Utilization of Wind Energy Potential on a Remote and Isolated Small Wastewater Treatment Plant. Smart Grid and Renewable Energy, 2, 293-299. http://dx.doi.org/10.4236/sgre.2011.23033

[14] Ramirez, J.M. (2011) Embedding PV and WF Models into Steady State Studies by an Optimization Strategy. Smart Grid and Renewable Energy, 2, 245-254. http://dx.doi.org/10.4236/sgre.2011.23027

[15] Hidayatullah, N., Stojcevski, B. and Kalam, A. (2011) Analysis of Distributed Generation Systems, Smart Grid Technologies and Future Motivators Influencing Change in the Electricity Sector. Smart Grid and Renewable Energy, 2, 216-229. http://dx.doi.org/10.4236/sgre.2011.23025

[16] Saleh, M.A.H. and Eskander, M.N. (2011) Sizing of Converters Interfacing the Rotor of Wind Driven DFIG to the Power Grid. Smart Grid and Renewable Energy, 2, 300-304. http://dx.doi.org/10.4236/sgre.2011.23034

[17] Wanxin, W. and Zequn, G. (2013) A Localization of Solow Growth Model with Labor Growth Pattern in China. Technology and Investment, 4, 24-26. http://dx.doi.org/10.4236/ti.2013.41B005

[18] Juraj, P., Ivan, B., Zuzana, Č. and Marian, R. (2013) Portfolio Selection by Maximizing Omega Function Using Differential Evolution. Technology and Investment, 4, 73-77. http://dx.doi.org/10.4236/ti.2013.41B012

[19] Varga, A., Hoau-Horváth, O., Szabó1, N. and Járosi, P. (2013) Blue Economy Innovation Impact Assessment with the GMR-Europe Model. Technology and Investment, 4, 213-223. http://dx.doi.org/10.4236/ti.2013.44025

[20] Broll, U., Wong, W.K. and Wu, M. (2011) Banking Firm, Risk of Investment and Derivatives. Technology and Investment, 2, 222-227. http://dx.doi.org/10.4236/ti.2011.23023

[21] Baranes, E. and Vuong, C.H. (2011) Ex-Ante Asymmetric Regulation and Retail Market Competition: Evidence from Europe's Mobile Industry. Technology and Investment, 2, 301-310. http://dx.doi.org/10.4236/ti.2011.24031 